\section{HUGO warning over broad patents on gene sequences}

[LONDON] The Human Genome Organization (HUGO), the international body that coordinates research into the sequences of the human genome, has confirmed its opposition to the patenting of "short sequences from randomly isolated portions of genes encoding proteins of uncertain functions".

Its statement, echoing concern expressed previously, coincides with news that the US Patent and Trademark Office had provisionally agreed to issue patents on expressed sequence tags (ESTs). The patent office had accepted the argument that the use of such tags as probes to identify specific DNA sequences demonstrates their clear 'utility' (see Nature 385, $670 \& 386,747 ; 1997$ ).

HUGO's Intellectual Property Rights Committee urges the US patent office and others that have adopted a similar position to rescind their decision and, in the meantime, strictly to limit the claims of patents to specified uses. "It would be untenable to make all subsequent innovation in which EST sequences would be involved in one way or other dependent on such patents," the statement says.

At the same time, the committee expresses caution about excessive commitment to the free use of sequence data, implicitly warning against any attempt to impose a blanket ban on the patenting of complete human genes. While reaffirming its view that large-scale sequencing laboratories should make raw sequence data freely available, the committee expresses the hope that this "will not unduly prevent the protection of genes as new drug targets" - arguing that such protection "is essential for securing adequate high-risk investments".

The HUGO statement argues that legislators should seek an international agreement on the introduction of a 'grace period', similar to that which exists in the United States, allowing researchers a period after the publication of their results in which they can still file for patent protection.

The panel that drafted the HUGO statement was chaired by Joseph Strauss, of the Max Planck Institute for Foreign and International Patent, Copyright and Competition Law in Munich. Its members included both industrial scientists, such as Peter Goodfellow of SmithKline Beecham, and academic researchers, such as John Sulston, director of the Sanger Centre in Cambridge, England.

It stresses that "only the policy of rapid publication and free availability of human genomic sequence information will secure further international co-operation of largescale sequencing centres".

\section{Africa spearheads bid for strict rules on biosafety}

[LONDON] Fifteen African countries unexpectedly seized the initiative last week at a meeting of the United Nations Biodiversity Convention by tabling detailed proposals calling on all signatories to the convention to accept tough regulations governing the use of genetically modified organisms.

Led by Ethiopia, the African proposals call for an all-embracing international biosafety protocol to govern the handling, transfer, use and release of all 'living modified organisms' (LMOs).

The proposals are being opposed by the European Union (EU) and the United States, as they appear to contravene an agreement made last year at the annual conference of the biodiversity convention. At that meeting, participating countries agreed that a biosafety protocol would cover only crossborder transport of LMOs (see Nature 382, 384; 1996).

Sateeaved Seebaluck, principal assistant secretary at the Ministry of Environment and Quality of Life in Mauritius, says Africa did not so much change its mind as exhibit a "delayed reaction" to the original consensus. "African countries were silent, but that did not mean we agreed with the EU position."

The African document was thrashed out last year in the Ethiopian capital Addis Ababa at a meeting of eight countries, including Zambia, Mali, Cameroon and Mauritius, as well as Ethiopia. A further nine countries signed up to the document last week at a meeting of the biosafety protocol working group in Montreal.

The document insists that the protocol should include detailed provisions for liability and compensation payments in the event of harm being caused by the use of LMOs.

Some claim that the African countries have been assisted in drawing up their proposals by at least one Western non-governmental organization; one name being mentioned is that of the Community Nutrition Institute in Washington DC.

African countries are calling for the protocol to take account of the social and economic consequences of biotechnology, such as the loss of revenue for countries whose exports are affected when countries stop importing traditionally grown crops in favour of growing or importing genetically modified ones.

European countries with links to Africa are understood to be trying to persuade African signatories not to adopt tough measures, which they believe could inhibit trade and agriculture. Most EU countries would prefer to leave detailed regulation of genetically modified organisms to national authorities.

Just before last week's meeting in Montreal, officials from French-speaking developed

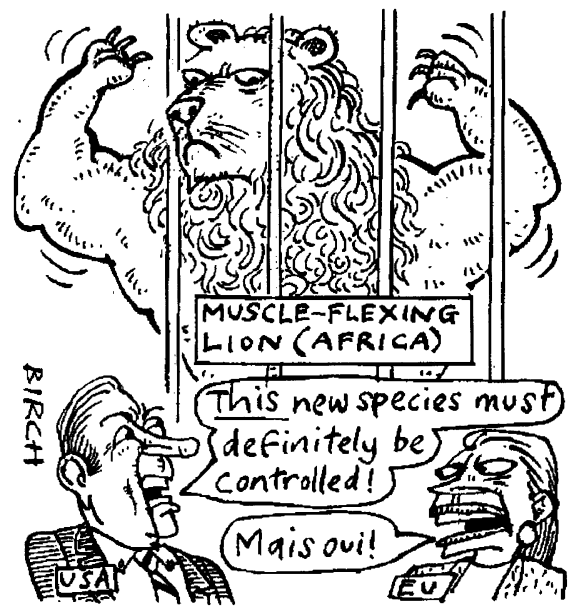

countries, including France, Canada and Switzerland, organized a two-day conference in the city with counterparts from Francophone Africa. The meeting was designed to help French-speaking African countries keep abreast of developments within the convention, as official UN biodiversity documents are not yet available in French.

But Yoke-Ling Chee, a representative of the environmentalist group Third World Network based in Penang, Malaysia, echoes the views of several observers by saying "there were rumours that the meeting may have been an attempt to lobby African countries to change their positions".

Seebaluck acknowledges that pressure will be put on African countries to modify their positions in the run-up to the next biosafety meeting in October, which is the deadline for submissions of proposed text for the protocol, and when hard negotiations will begin. $\mathrm{He}$ points out that South Africa is already said to be uneasy, particularly on the questions of liability and the economic implications of biotechnology.

Significantly, however, developing countries remain divided on the content and scope of the proposed biosafety protocol. Countries in the Far East and Latin America that are keen to grasp biotechnology to enhance trade and agriculture are broadly opposed to tough regulations. Less developed countries are in favour of such measures.

India, which belongs to the former group, has not yet formally shown its hand. But sources close to the Indian government say that it would not want to sign up to a protocol that could impede possible commercial advantages from biotechnology.

Many developing countries that were in favour of strong regulations two or three years ago are said to have privately changed their positions, but to be unprepared as yet to say so in public. 